coloproctology $2011 \cdot 33: 6-7$

DOI 10.1007/s00053-011-0161-8

Online publiziert: 30. Januar 2011

(c) Springer-Verlag 2011

\section{T. Hager}

Kronach

\title{
Die neue coloproctology
}

Sehr geehrte Leserin, sehr geehrter Leser der Zeitschrift coloproctology,

es wird Sie sicher erstaunen, vom $\mathrm{He}$ rausgeber ein Editorial zu lesen, das erste überhaupt!

Ich gestehe, ich lese lieber eingesandte Artikel, akzeptiere oder lehne ab, versuche gute Beiträge zu finden, z. B. anhand von Vorträgen, gehalten am diesjährigen 37. Deutschen Koloproktologen Kongress in München. Derartige Kongresse fördern den wissenschaftlichen Informationsaustausch, regen zur Diskussion an und bieten eine Plattform zur Fort- und Weiterbildung.

Der Grund für dieses Editorial ist das neue Cover der Zeitschrift, welches mir sehr gut gefällt. Im Zuge der Weiterentwicklung wurde im letzten Jahr ein modernes Layout der Artikel innerhalb des

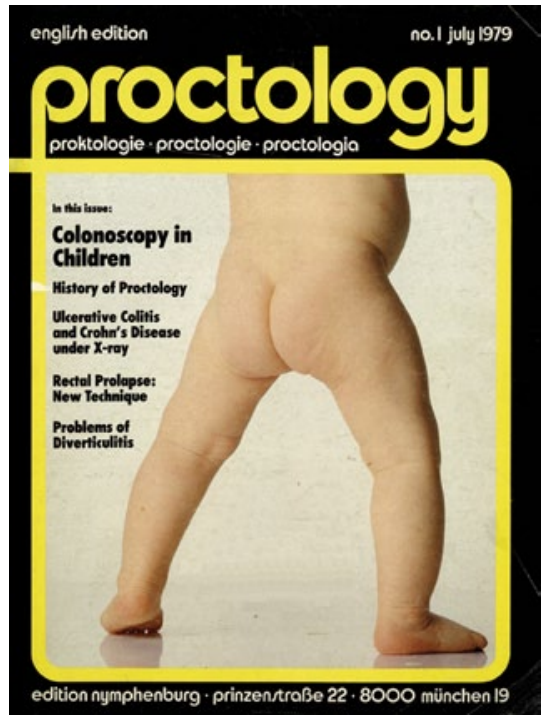

Abb. $1 \Delta$ Erste englische Ausgabe der coloproctoloy (1979)
Hefts eingeführt. Im Jahr 2011 wird nun das Erscheinungsbild mit einer neuen Covergestaltung abgerundet. Die Zeitschrift coloproctology reiht sich jetzt auch visuell in eine Vielzahl guter medizinischer Journale bei Springer Medizin ein.

\section{(D) Die Zeitschrift coloproctology reiht sich jetzt auch visuell in eine Vielzahl guter medizinischer Journale bei Springer Medizin ein}

Die Idee eines optisch ansprechenden Covers, welches in unseren Fachbereich passt, begann bereits bei der Gründung der Zeitschrift. In diesem Zusammenhang möchte ich auf die erste Ausgabe der coloproctology von 1979 erinnern. Unter der Leitung von Wolfgang Frank erschien die Zeitschrift mit einem Titelbild, das von vielen als Provokation angesehen wurde: dem Po seiner kleinen Tochter (- Abb. 1). Das neue Coverkonzept wiederum verweist auf einzelne Beiträge der jeweiligen Ausgabe und bietet so einen Vorgeschmack auf das Heft.

An der interdisziplinären Gestaltung der Zeitschrift von Wolfgang Frank hat sich all die Jahre nichts geändert, sozusagen Koloproktologie für alle Fachdisziplinen. Auch der Verlag Urban \& Vogel hat dieses Prinzip beibehalten. Im Laufe des letzten Jahres gab es innerhalb der Redaktion einige Veränderungen. Die Zeitschrift wird nun von Monika Kretz und Christiane Jurek betreut, die das Ziel einer praxisbezogenen und fachlich hochwertigen Zeitschrift weiterhin verfolgen und das Konzept stets weiterentwickeln werden. In diesem Zusammenhang möchte ich Daniela Oesterle für die lange sehr gute Zusammenarbeit danken und an ihr Editorial „30 Jahre coloproctology“ (2010, 32:7-7) erinnern.

Ich wünsche der Zeitschrift mit neuem Erscheinungsbild viel Erfolg, vor allem viele gute nationale und internationale Beiträge, um coloproctology noch bekannter zu machen, einen ImpactFaktor zu erlangen und die Zeitschrift als Ort wissenschaftlicher Publikationen auch junger Wissenschaftler fest $\mathrm{zu}$ etablieren. Lassen Sie mich mit einem Ausspruch des ehemaligen Vorstandsvorsitzenden der deutschen Lufthansa $\mathrm{GmbH}$, einer ständig expandierenden Luftlinie, Wolfgang Mayrhofer, schließen: „Bleiben Sie uns gewogen!“

Ihr
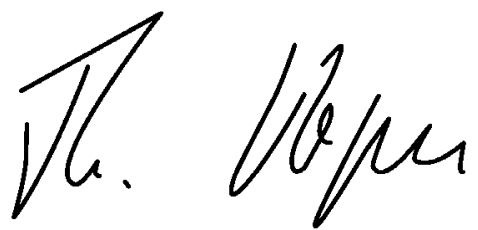

T. Hager

\section{Korrespondenzadresse}

Prof. Dr. T. Hager

Dobersgrund 87, 96317 Kronach

th.hager@web.de 
Hier steht eine Anzeige.

黛 Springer 